\title{
Evaluating data quality collected by volunteers for first-level inspection of hydraulic structures in mountain catchments
}

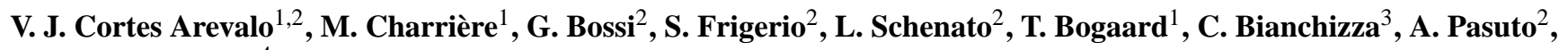 \\ and S. Sterlacchini ${ }^{4}$ \\ ${ }^{1}$ Delft University of Technology, Delft, the Netherlands \\ ${ }^{2}$ Italian National Research Council, Institute for Geo-hydrological Protection, CNR-IRPI, Padova, Italy \\ ${ }^{3}$ Institute of International Sociology Gorizia, ISIG, Gorizia, Italy \\ ${ }^{4}$ Italian National Research Council, Institute for the Dynamic of Environmental Processes, CNR-IDPA, Milan, Italy \\ Correspondence to: V. J. Cortes Arevalo (juliette.cortes@irpi.cnr.it)
}

Received: 15 April 2014 - Published in Nat. Hazards Earth Syst. Sci. Discuss.: 22 May 2014

Revised: 30 July 2014 - Accepted: 31 July 2014 - Published: 6 October 2014

\begin{abstract}
Volunteers have been trained to perform first-level inspections of hydraulic structures within campaigns promoted by civil protection of Friuli Venezia Giulia (Italy). Two inspection forms and a learning session were prepared to standardize data collection on the functional status of bridges and check dams. In all, 11 technicians and 25 volunteers inspected a maximum of six structures in Pontebba, a mountain community within the Fella Basin. Volunteers included civil-protection volunteers, geosciences and social sciences students. Some participants carried out the inspection without attending the learning session. Thus, we used the mode of technicians in the learning group to distinguish accuracy levels between volunteers and technicians. Data quality was assessed by their accuracy, precision and completeness. We assigned ordinal scores to the rating scales in order to get an indication of the structure status. We also considered performance and feedback of participants to identify corrective actions in survey procedures. Results showed that volunteers could perform comparably to technicians, but only with a given range in precision. However, a completeness ratio (question / parameter) was still needed any time volunteers used unspecified options. Then, volunteers' ratings could be considered as preliminary assessments without replacing other procedures. Future research should consider advantages of mobile applications for data-collection methods.
\end{abstract}

\section{Introduction}

There is an increasing interest in the use of citizen-based approaches to better understand the environment and hazardrelated processes. To that end, there are different datacollection approaches according to the citizens' skills and time of involvement, e.g., crowdsourcing (Hudson-Smith et al., 2008), volunteered geographic information (Goodchild, 2007) or facilitated-volunteered geographic information (Seeger, 2008). Moreover, scientists have increasingly considered management approaches based upon the broader concept of citizen science (Bonney et al., 2009). Thereby, volunteers are enlisted and trained according to survey and management needs (Devictor et al., 2010).

In disaster risk management, citizen science is linked to European and worldwide directives, such as the Hyogo framework (European Commission, 2007; United Nations, 2005). Such directives promote citizen involvement to build a culture of resilience before, during and after a disaster strikes (European Commission, 2012). Therefore, modern approaches for emergency management promote exchange of information between local authorities and volunteer groups to support preparedness and preventive actions (Enders, 2001).

Hydro-meteorological events in mountain areas are often caused by multiple and sudden onset floods and debris flows. Traditionally, hazard mitigation in the European Alps is mainly organized by implementing structural measures. However, the increasing frequency and influence of flow and 
sediment processes also affect the functional status of hydraulic structures, and vice versa (Holub and Hübl, 2008).

The impact (i.e., damage) is evident to structures for debris-flow control, such as check dams. Evidence is also found in the potential aggravation of flood hazard at the location of bridges and culverts due to blocking material such as debris, large wood and other residues (Mazzorana et al., 2010). Stability of protection works is often threatened by the erosion level at stream banks.

The need to enhance data-collection approaches to support risk-management strategies is widely acknowledged (e.g., Molinari et al., 2014). Besides situations where financial and human resources are limited, scientific monitoring may be subject to additional complexity under dynamic environmental conditions or remote settings (de Jong, 2013).

Moreover, frequent inspection of hydraulic structures is especially important in mountain basins. Therefore, opportunities in promoting citizen science projects stem from the increasing frequency, timeliness and coverage of surveillance activities (Flanaging and Metzger, 2008). To be useful, survey procedures should be tested and adapted according to quality requirements of decision-makers (Bordogna et al., 2014; EPA, 1997; Goodchild and Li, 2012; Gouveia and Fonseca, 2008).

Experiences of citizen science include data collection regarding water quality and biological aspects (Engel and Voshell Jr., 2002; Fore et al., 2001; Nicholson et al., 2002); forestry and ecosystem rehabilitation (Brandon et al., 2003; Gollan et al., 2012); biodiversity (Snäll, 2011); stream monitoring (Bjorkland et al., 2001; Yetman, 2002) and hydrological processes (Cifelli et al., 2005; Rinderer et al., 2012). Despite the variety of projects, limited research has been devoted to evaluating the quality of citizen-based data (Danielsen et al., 2005). Furthermore, scientists and decision-makers have a general lack of confidence due to the limited accuracy, non-comparability and incompleteness of citizen-collected data (Riesch and Potter, 2014; Conrad and Hilchey, 2011).

In spite of the challenges for citizen involvement, precision and completeness of largely collected data depends on the exhaustiveness of the inspection procedures (Galloway et al., 2006). Therefore, training activities are often required before starting the inspection campaigns. However, the extension of these training sessions should consider available time, number and type of participants (Tweddle et al., 2012). To that end, Jordan et al. (2011) suggested that identification of technical data should be restricted while more general indicators can still be accurately obtained. Those indicators may be quantitative and qualitative aspects that are easily recognizable from visual inspections (Gommerman and Monroe, 2012; Gouveia et al., 2004). Then, qualitative field methods are generally based on rating scales to report inspected conditions.
This study considers regular inspections with citizenvolunteer groups that are promoted by civil protection and local authorities of Friuli Venezia Giulia (FVG), Italy. We involved 11 technicians and 25 volunteers on a data-collection exercise. Participants were invited according to their location. Thus, 15 out of 25 volunteers were members of civil-protection groups in neighboring municipalities. In all, 10 university students were also volunteers within a supplementary academic activity.

In this paper, we evaluate data quality on preliminary inspections of bridges and check dams. Therefore, we address the following research questions: (1) how well were participants able to report on the functional status by distinguishing between available rating classes? (2) How effectively were data collected by volunteers compared to those collected by technicians? (3) How can survey procedures be improved? To that end, Sect. 2 describes the methodology for data collection. In Sect. 3, we evaluate data quality by their accuracy, precision and completeness. Finally, we highlight in the discussion's and conclusion's (Sects. 4 and 5) key points for the practical use of citizen-based data.

\section{Methods}

In the first step of the methodology, we defined target groups. The participants' groups comprised of volunteers and technicians to evaluate the data quality. In the second step, two inspection forms were designed for bridges and check dams. The forms were created to carry out inspections with trained volunteers.

Despite available procedures for technicians, the volunteers' involvement demands more structured and simpler forms to inspect the functional status. Similar to Yetman (2002), we used rating scales to standardize collected data in distinguishing minor problems from more serious concerns. The rating scales included visual schemes to guide inspectors. In addition, the latter were required to take a photo to support their choices.

Finally, we organized a data-collection exercise to carry out first-level inspection of six structures, hereafter referred to as "inspection tests". There was 1 day for the training session and 1 day for the inspection tests. Participants were divided between control and learning groups to identify potential improvements in survey procedures.

\subsection{Participants' groups}

Citizens were involved in the form of civil-protection volunteers due to safety limitations and accessibility to hydraulic structures in mountain catchments. Citizens enrolled as civilprotection volunteers traditionally received formative, informative and safety procedures while specialized training is selectively provided (Protezione Civile FVG, 2009). 
Table 1. Participants' distribution between learning groups (LGs) and control groups (CGs).

\begin{tabular}{|c|c|c|c|}
\hline Participant's number & & 2-day LG & 1-day CG \\
\hline Civil protection volunteers & 15 & $\begin{array}{l}8 \text { from Pontebba } \\
2 \text { from Chiusaforte } \\
2 \text { from Dogna }\end{array}$ & $\begin{array}{l}1 \text { from Pontebba (Date } 1) \\
1 \text { from Dogna (Date 3) } \\
1 \text { from Malborghetto (Date 4) }\end{array}$ \\
\hline Geo-sciences students & 8 & $4^{*}$ & 4 \\
\hline Social science students & 2 & 2 & No participants \\
\hline Volunteers (Vs) & 25 & 18 learning (of which 14 testing) & 7 testing \\
\hline $\begin{array}{l}\text { Civil protection }(\mathrm{CP}) \\
\text { Forestry service }(\mathrm{FS}) \\
\text { Geological survey }(\mathrm{GS})\end{array}$ & 11 & $\begin{array}{l}3 \text { and } 1^{*} \text { from } \mathrm{CP} \\
1 \text { from } \mathrm{FS} \\
1 \text { from } \mathrm{GS}\end{array}$ & $\begin{array}{l}1 \text { from CP (Date 3) } \\
1 \text { from FS (Date 1) } \\
3 \text { from GS (Date 2) }\end{array}$ \\
\hline Technicians (Ts) & 11 & 6 learning (of which 5 testing) & 5 testing \\
\hline Participants & 36 & 24 learning (of which 19 testing) & 12 testing \\
\hline
\end{tabular}

* LG participants that attended only 1-day (pre-test and test 1 for bridges and check dams).

In addition, we widened the range of participants with students to account for assumed differences in preliminary knowledge to fill the form. Then, volunteers included geology students and students from a master's course on cooperation, both from the University of Trieste. The technicians were employees from regional services with competences for the inspection of hydraulic structures in the mountain community.

Volunteers (Vs) and technicians (Ts) joined the activity according to their time-availability (Table 1). The control group (CG) carried out the inspection tests without attending the learning session. Most citizen-volunteers were present in the learning group (LG) as they are the target group of campaigns promoted by civil protection. Students of geosciences were only available for the inspection tests during the first day. Their involvement was important to facilitate knowledge exchange during outdoor learning. Then, they were equally divided into a volunteers' learning group (VLG) and a volunteers' control group (VCG).

During registration to the data-collection exercise, participants were asked to fill a questionnaire to characterize participants' groups (Table A1). Gathered information included demographics such as age, gender and level of education, as well as period of residence in the Fella Basin and FVG region. In addition, we measured the experience with hydrometeorological hazards (i.e., floods, debris flows and landslides). The questionnaire also included 20 questions to assess a prior knowledge of participants of debris-flow phenomena, functionality of check dams and culverts, as well as emergency security guidelines.

\subsection{Design of the inspection forms}

Table 2 summarizes the forms' layouts divided by sections. We defined the latter with four risk managers of civil protection, the geological survey and the forestry service of FVG.
Section I identifies the inspector. Section II comprises simplified information on location, type, use and presence of connected structures, if available. Section III accounts for the level of accessibility, presence of stream water, occurrence of rainfall and snow. Thus, section III becomes relevant for comparing between campaigns carried out at different time periods. Thereafter, section IV of the form refers to the functional status of the inspected structure. Functional status is the susceptibility or physical conditions of the structure that may affect the function type for which it was designed or built (Uzielli et al., 2008). Furthermore, the functional status is inspected by looking at three parameters, according to the structure type.

Parameters in section IV are comprised of a maximum of four questions. For example, questions for check dams in parameter A are: (1) is the stream flow passing where it should be? (2) What is the status of the check dam? (3) How visible is the basis of the structure? (4) Is there any protection for scouring at the downstream bottom of the check dam? Questions, rating options and visual schemes were defined according to inspection procedures for technicians. Those were mainly for check dams (Jakob and Hungr, 2005; Provinzia Autonoma di Bolzano, 2006; von Maravic, 2010; Province of British Columbia, 2000) and bridges (Burke Engineering, 1999; Ohio Department of Transportation, 2010; Servizio Forestale FVG, 2002). The inspection forms adopted in this study are available as the Supplement.

For the case of bridges, parameter A focuses on the opening for the water flow and erosion of the pillar or abutments. Parameter B assesses levels of lateral obstruction, either at the structure location or at the stream channel. Therefore, questions for these parameters were aimed at identifying morphological changes immediately upstream, downstream and at the structure location. Such changes relate to either local erosion at protection structures and abutments, deposition phenomena that is somehow perennial with presence 
of vegetation, or clogging of critical flow sections. Finally, it accounts for additional elements, such as pipes, when they reduce the stream cross section.

We also included a question referring to the maximum free height of the structure. However, it was, in the end, not considered due to safety limitations for citizen volunteers when accessing the stream channel. Limitations are based on the dynamic distribution of deposits and eroding surfaces along steep mountain channels (Remaitre et al., 2005). Therefore, volunteers should follow safety procedures according to the environmental and meteorological conditions during the inspection period.

For check dams, the focus of parameter $\mathrm{A}$ is on the status of the structure itself and downstream scouring. Parameter B distinguishes between consolidation and open check dams. Then, upstream obstruction is limited to the open check dam type. That distinction is due to the relevance of open check dams for retention of sediments, if there is a retention basin connected to the structure. Therefore, we included a "Does not apply" option for inspecting consolidation check dams.

In contrast, parameter $\mathrm{C}$ addresses the same questions for bridges and check dams. It refers to the worst condition while looking at the presence of protection works and erosion level at the stream banks. Then, we established a control distance of $20 \mathrm{~m}$ upstream and downstream of the structure. This distance was defined to reduce variability of assessments during the inspection. The $20 \mathrm{~m}$ allow inspectors to observe and to take pictures, even if accessibility to the structure is restricted. Section V of the form reports the critical infrastructure within the same control distance. Finally, section VI distinguishes required actions to follow up the inspection based on the options provided in the form.

Data-quality evaluation focuses on sections IV and VI of the inspection form. Table 3 summarized the rating scales we used. When the question itself did not specify the location to report, a multiple choice was included by specifying the problem's location: right, left or in correspondence with the structure. In addition, all questions had alternative options to report unspecified answers such as "I don't know" and "Could not be answered". The latter represents conditions at the structure location (e.g., water level) that did not allow inspectors to provide an assessment.

In addition, we assigned ordinal scores to the rating classes to get an indication on the functional status. For the dataquality evaluation, we aggregated scores according to the given range in precision while generalizing the rating scales.

\subsection{Data-collection exercise}

The data-collection exercise was carried out in the municipality of Pontebba (FVG, Italy) within the mountain community in the Fella Basin (Fig. 1a). The only settlement with over 4000 inhabitants is Tarvisio, bordered by Austria and Slovenia. The Fella catchment has an area of $700 \mathrm{~km}^{2}$, with a mean altitude of $1140 \mathrm{~m}$ a.s.l. It consists mostly of lime- stone and it is characterized by steep slopes and high tectonic grade. The area is prone to landslides, flash floods and debris flows.

The latest severe alluvial event was on 29 August 2003. The total rainfall amount of the event was equal to $389.6 \mathrm{~mm}$. Detected intensities were particularly strong for values corresponding to 3 and $6 \mathrm{~h}$ (Borga et al., 2007). The event caused severe damage, created gullies and expanded existing river beds. The most affected villages were Ugovizza, Valbruna, Malborgehtto and Pontebba (Calligaris and Zini, 2012).

After the 2003 event, technical services updated the inventory of debris flows. Civil protection realized several mitigation measures in the affected areas. The basin authorities produced an updated version of the hazard maps, P.A.I-FELLA (ADBVE, 2012). Thus, $22 \%$ of total check dams and $50 \%$ total of bridges within Fella Basin are accounted at the different hazardous areas defined in the P.A.I. upstream of the Pontebba location. That corresponds to 230 and 115 structures respectively.

Civil protection selected the structures for the inspection tests (Fig. 1b). The complexity of the inspection tests differed according to the functional status of the structures. Then, structures for the inspection tests accounted for a range from minimal to serious concerns. Structures also included connected elements, such as retention basins and secondary check dams for scouring protection.

Finally, Table 4 describes the organization of the exercise, divided by sessions and inspection tests. The registration questionnaire was open until the exercise day, which took place on May 2013. See the website of the activity ${ }^{1}$ for more details on the questionnaire and training material.

After a common introductory session, participants inspected the same structures according to the CG or LG program. Every test took $15 \mathrm{~min}$ on average, which was actually faster than expected. First, all participants carried out an indoor pretest by looking at a poster. Then, the CG initiated inspections directly in the field without attending the learning session. The CG program was on different dates based on the participants' availability.

Instead, the LG continued their first-day with the learning session. The learning had an indoor program followed by an outdoor session that included the structures of the pretest. In the outdoor session, the LG was divided into teams with representatives of each participant's group (one technician, civilprotection volunteers and one student). At first, each participant compiled the test 1 for check dams and bridges. Then, they filled it out by teams for knowledge exchange. Senior technicians clarified further aspects, if needed. On the second day, the LG continued with test 2 and 3, divided in two groups to reach the structure location. At the end, all participants provided feedback and submitted the pictures they took during the inspections, if any.

\footnotetext{
${ }^{1}$ https://horatius.irpi.pd.cnr.it/changes-fella/changes-fella/ index.php/relazione-dell-attivita
} 
Table 2. Form's layout for bridges and check dams.

\begin{tabular}{|c|c|}
\hline Sections & Aim of each section \\
\hline I. Inspector's name and period of the inspection & $\begin{array}{l}\text { Identify person responsible for form compiling } \\
\text { Identify time and inspection period based on rainfall conditions } \\
\text { during last } 24 \mathrm{~h} \text {, if known }\end{array}$ \\
\hline II. Structure and function type & Precompiled with data available from regional databases of hydraulic structures \\
\hline III. Inspection conditions & Distinguish conditions of regular inspections from those to intensify surveillance \\
\hline $\begin{array}{l}\text { IV. Functional status: } \\
\text { A. Condition of the structure } \\
\text { B. Level of obstruction at the structure }\end{array}$ & $\begin{array}{l}\text { Distinguish among the following possible actions: } \\
\text { No action is required } \\
\text { Requires routine cleaning of blockages by hand } \\
\text { with a maximum group of } 10 \text { volunteers }\end{array}$ \\
\hline $\begin{array}{l}\text { C. Presence of protection works and } \\
\text { erosion level at the stream bank }\end{array}$ & $\begin{array}{l}\text { Requires cleaning with support of equipment } \\
\text { Second level inspection; actions other than cleaning are required }\end{array}$ \\
\hline V. Presence of anthropic elements & Refer critical infrastructure next to the structure \\
\hline VI. Synthesis of the inspection & Provide general recommendation from available options \\
\hline
\end{tabular}

Table 3. Rating scales used in the inspection form.

\begin{tabular}{|c|c|c|c|c|}
\hline $\begin{array}{l}\text { Rating classes } \\
\text { (Scores) }\end{array}$ & Criteria & Score's meaning & $\begin{array}{l}\text { Generalized classes } \\
\text { (Precision range) }\end{array}$ & Questions \\
\hline $\begin{array}{l}\text { Five classes } \\
(1,2,3,4 \text { and } 5)\end{array}$ & $\begin{array}{l}\text { Minimum to } \\
\text { maximum } \\
\text { concerns }\end{array}$ & $\begin{array}{l}\text { 1: Best condition } \\
5: \text { Worst condition }\end{array}$ & $\begin{array}{l}\text { Three classes } \\
(1-2,3 \text { and } 4-5)\end{array}$ & $\begin{array}{l}\text { Bridges: B1 \& B2 } \\
\text { Check dams: A2, A3, B1 \& B3 } \\
\text { Both: C2.1, 2, } 3 \& 4\end{array}$ \\
\hline $\begin{array}{l}\text { Three classes } \\
(1,3 \text { and } 5)\end{array}$ & $\begin{array}{l}\text { Differences } \\
\text { are not for } \\
\text { five classes }\end{array}$ & $\begin{array}{l}\text { 1: Best condition } \\
\text { 3: Medium condition } \\
\text { 5: Worst condition }\end{array}$ & $\begin{array}{l}\text { Three classes } \\
\text { (None) }\end{array}$ & Check dams: A4 \& B1 \\
\hline $\begin{array}{l}\text { Three classes } \\
(1,4 \text { and } 5)\end{array}$ & $\begin{array}{l}\text { Relevance } \\
\text { to present } \\
\text { aspects }\end{array}$ & $\begin{array}{l}\text { 1: Total absence } \\
\text { 4: Presence } \\
\text { 5: Presence beyond reference aspect }\end{array}$ & $\begin{array}{l}\text { Two classes } \\
(1 \text { and } 4-5)\end{array}$ & $\begin{array}{l}\text { Bridges: A1* } \\
\text { Check dams: } \mathrm{A} 1^{*} \\
\text { Both: } \mathrm{C} 1.1,2,3 \& 4\end{array}$ \\
\hline $\begin{array}{l}\text { Two classes } \\
(1 \text { and } 5)\end{array}$ & Yes/no & $\begin{array}{l}\text { 1: Absence } \\
\text { 5: Presence }\end{array}$ & $\begin{array}{l}\text { Two classes } \\
\text { (None) }\end{array}$ & Bridges: A2*, A3 \& B3* \\
\hline $\begin{array}{l}\text { Synthesis } \\
(1,2,4 \text { and } 5)\end{array}$ & & $\begin{array}{l}\text { Management options for } \\
\text { synthesis of the inspection }\end{array}$ & $\begin{array}{l}\text { Two classes } \\
(1-2 \text { and } 4-5)\end{array}$ & Section VI of the form \\
\hline
\end{tabular}

* Includes multiple choice to specify the location of the problem.

\section{Evaluation on the quality of collected data by volunteers}

Tables 5 and 6 summarize results according to the component questions per parameter. Mean ordinal scores $(\bar{X})$ and standard deviations $(\mathrm{SD})$ were calculated from the ratings that participants reported in test 1,2 and 3.

Then, we evaluated how effectively data were collected by Vs as compared to that collected by Ts. Figures 2-6 summarize results according to the pretest, tests 1, 2 and 3. Distinction was done between Vs and Ts within participants of the learning and control groups. For that purpose, a frequency analysis was applied to the ordinal scores that Table 3 de- fines. This consideration was based upon the relatively low sample, size and difference in number between the groups. We referred to the mode score for the data evaluation as it represents the class with the highest frequency. In addition, we used the following criteria to assess the quality of collected data (EPA, 1997, p. 19-20):

- Accuracy is a "degree of agreement between the data collected and the true value on the condition being measured". Then, we referred to as "true value" as the mode score for Ts in the learning group. Figures 2-6 aggregate the relative frequencies in four frequency classes with reference to the true value: equal to or larger than 
a)
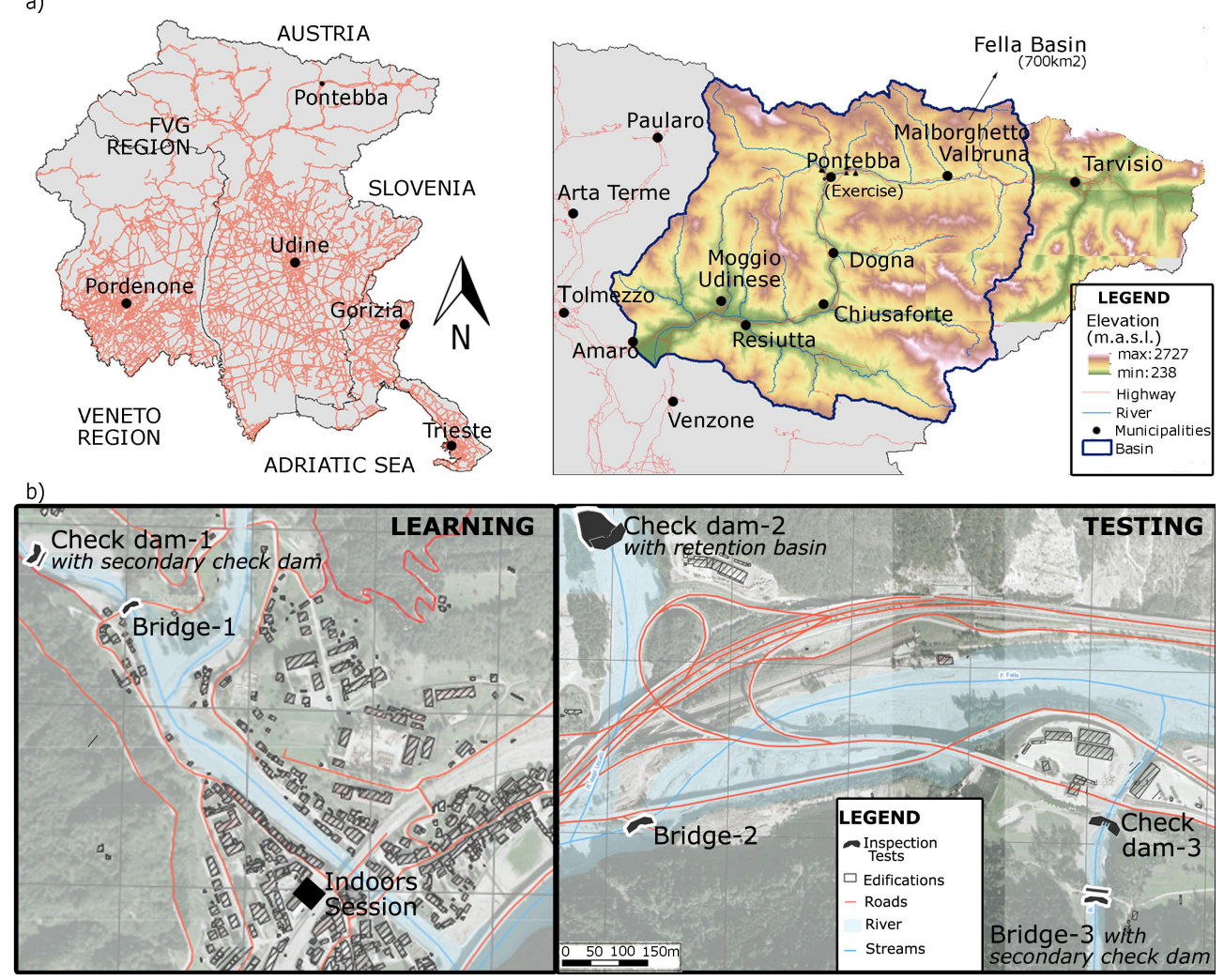

Figure 1. Study area: (a) overview of the study area and Fella Basin. (b) Map indicating the location of the structures for the inspection tests.

Table 4. Description of the data-collection exercise.

\begin{tabular}{|c|c|c|c|c|}
\hline & \multirow{2}{*}{$\begin{array}{l}\text { Session } \\
\text { (Duration) }\end{array}$} & \multirow{2}{*}{$\begin{array}{l}\text { Inspection test } \\
\text { (Structure) }\end{array}$} & \multicolumn{2}{|l|}{ Description of activities } \\
\hline & & & 2-day LG & 1-day CG \\
\hline (1) & $\begin{array}{l}\text { Registration } \\
\text { (1 month) }\end{array}$ & \multicolumn{3}{|c|}{ Filling the registration questionnaire. } \\
\hline (2) & $\begin{array}{l}\text { Introduction } \\
(1 \mathrm{~h})\end{array}$ & $\begin{array}{l}\text { Pretest with a poster } \\
\text { (Bridge } 1 \text { and check dam 1) }\end{array}$ & $\begin{array}{l}\text { Scope of the activity. } \\
\text { Safety advice and recommendations } \\
\text { for form compiling. } \\
\text { Pre-test to establish the initial } \\
\text { understanding of participants to fill the form. }\end{array}$ & \\
\hline (3a) & $\begin{array}{l}\text { Indoors learning } \\
(3 \mathrm{~h})\end{array}$ & \multicolumn{2}{|c|}{ Presentations of $45 \mathrm{~min}$ separated by breaks in-between. } & Participants divided in four groups. \\
\hline$(3 b)$ & $\begin{array}{l}\text { Outdoor learning } \\
(3 \mathrm{~h})\end{array}$ & $\begin{array}{l}\text { Test } 1 \\
\text { (Bridge } 1 \text { and check dam 1) }\end{array}$ & $\begin{array}{l}\text { Participants divided in two teams } \\
\text { guided by a senior technician. } \\
\text { Individual form compiled for two structures. } \\
\text { Team divided in five sub teams of five participants. } \\
\text { Group form compiled per sub team. }\end{array}$ & $\begin{array}{l}\text { Each group made the test in } \\
\text { one of three optional dates. } \\
\text { Individual form compiled } \\
\text { for six structures. }\end{array}$ \\
\hline (4) & $\begin{array}{l}\text { Testing } \\
(3 \mathrm{~h})\end{array}$ & $\begin{array}{l}\text { Test } 2 \text { and } 3 \\
\text { (Bridge } 2 \text { and 3) } \\
\text { (Check dam } 2 \text { and 3) }\end{array}$ & $\begin{array}{l}\text { Participants divided in two teams to minimize interaction. } \\
\text { Individual forms compiled for four structures }\end{array}$ & \\
\hline (5) & Feedback & Feedback form ( $15 \mathrm{~min})$ and & luring learning sessions. & \\
\hline
\end{tabular}

90, 70-90 and 50-70\%, and smaller than 50\%. We chose this aggregation to distinguish different accuracy levels for each group. In addition, we assumed agreement among group members when a question had a relative frequency of at least $70 \%$. Then, the overall agree- ment per parameter was calculated by the ratio question / parameter, i.e., the number of questions with frequencies of at least $70 \%$ between total questions per parameter. 


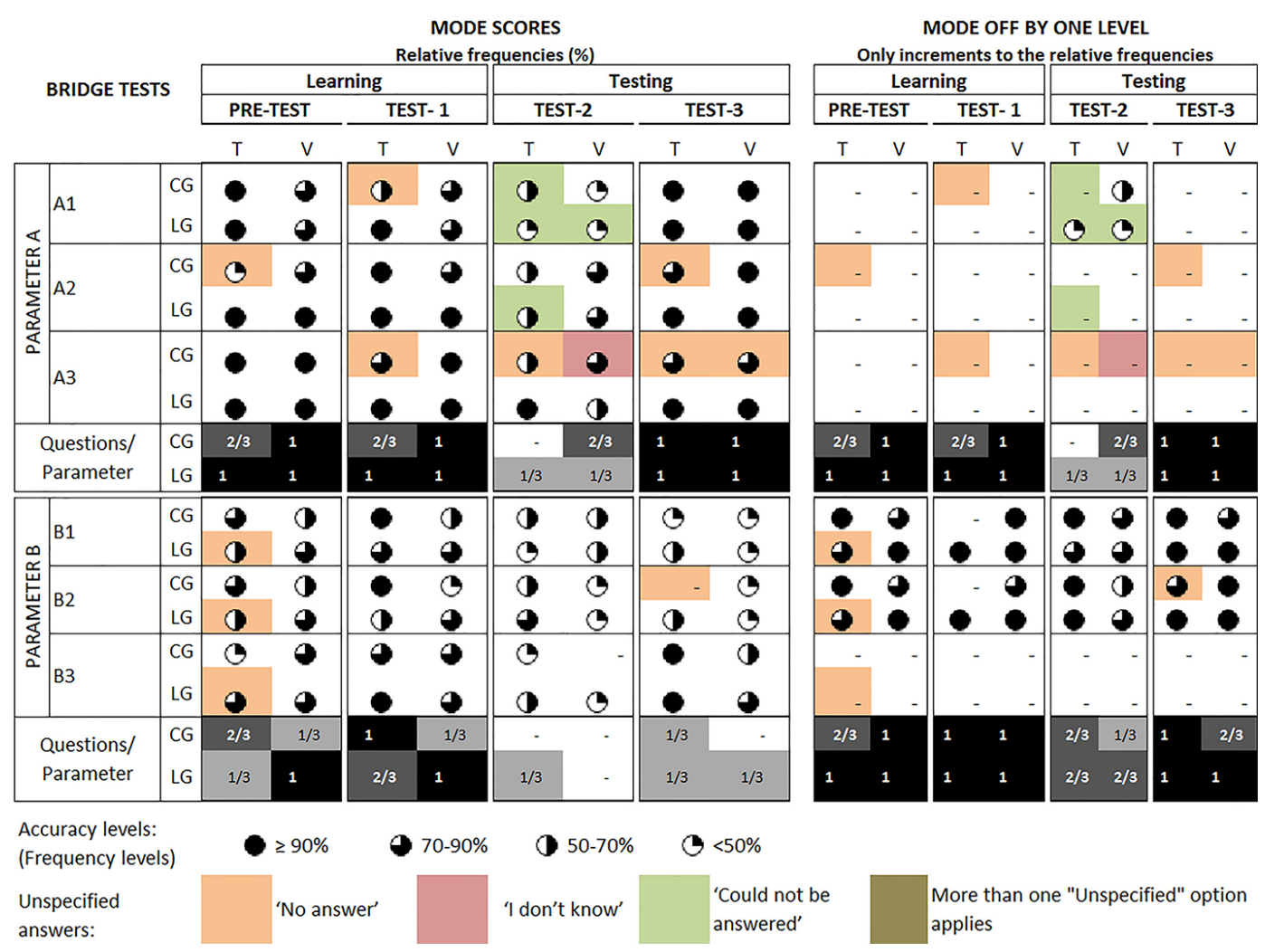

Figure 2. Relative frequencies for Vs and Ts of learning groups (LGs) and control groups (CGs). Parameters A and B in inspection tests for bridges.

- Precision "refers to how well data collected are able to reproduce the result on the same group". For all participants, we represented precision by using the standard deviation (SD) in Tables 5 and 6. Instead, in Figs. 26 , we compare each group while looking at the mode scores and the mode-off by one level. The mode-off is a range in precision given by generalizing the extreme scores of the rating classes. For example, according to Table 3, we generalize rating scales from five to three classes by grouping: very low to low concerns, medium concerns and high to very high concerns. Those are ordinal scores 1 and 2 on one side; scores 4 and 5 on the other. Mode-off by one level in Figs. 2-6 only distinguished questions where the scale generalization brought forth increments to the relative frequencies.

- Completeness is the "measure of the amount of valid data actually obtained vs. the amount expected to be obtained". In Tables 5 and 6, completeness is evaluated by the amount of answers obtained between the rating scales as compared to the selection of unspecified answers. In Figs. 2-6, we evaluated completeness by distinguishing questions with relative frequencies larger than $14 \%$ in the options: "I don't know", "Could not be answered" and "No answer". We chose a threshold of $14 \%$ to highlight questions with the lower complete- ness. It corresponds approximately to an absolute frequency of one participant in the control group or two participants in the learning group.

Other criteria, such as comparability and representativeness, were only considered in designing the form. "Comparability represents how well data from one form can be compared to data from another. Representativeness is the degree to which collected data actually represent the structure being inspected." (EPA, 1997, p. 19-20). Then, we referred to comparability by using a standard form for bridges and check dams. For representativeness, we required a photo record from the inspector to support their choices and to provide additional information for the later examination of inspections.

Finally, we used comments provided by participants during the sessions and the comments provided in the feedback form to define corrective actions (Table 7). Following subparts present results according to specific aspects for bridges and check dams, then into common aspects for both structures.

\subsection{Functional status of bridges for $A$ and $B$ parameters}

Table 5 shows that $\mathrm{A}$ and $\mathrm{B}$ parameters in test 1 have mean scores between 1 and 2 in the functional status. Lower ordinal scores represent the best condition for inspected aspects 


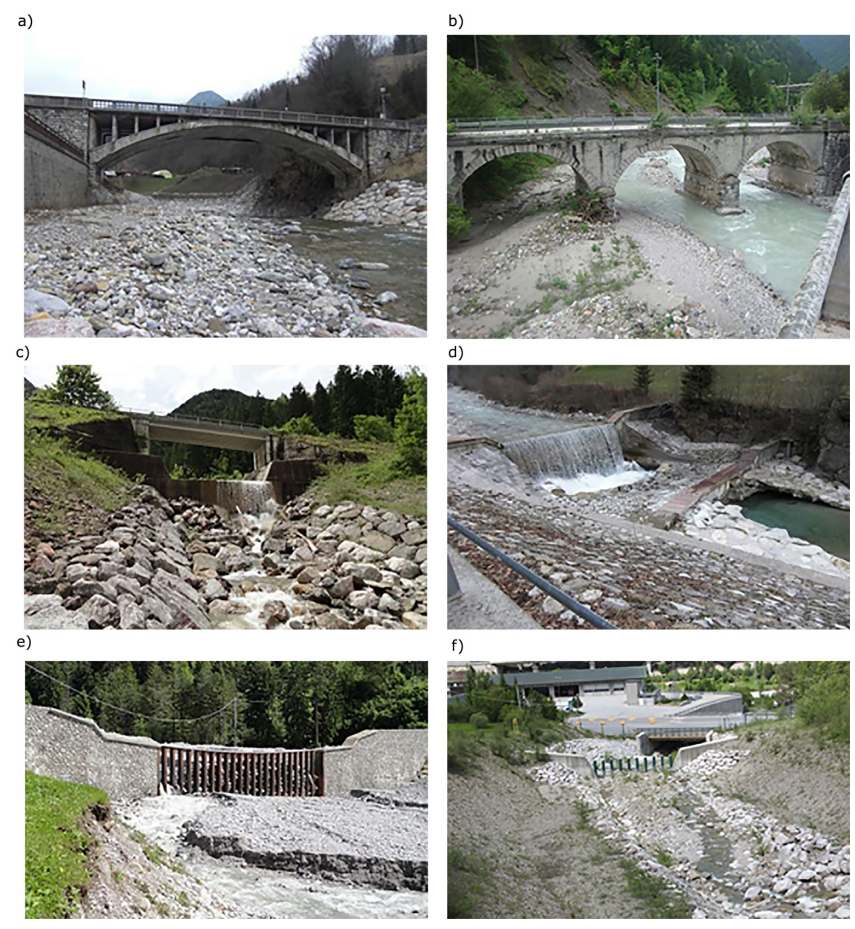

Figure 3. Photo record of the structures inspected: (a) upstream view of bridge 1: pretest and test 1. (b) Upstream view of bridge 2: test 2. (c) Upstream view of bridge 3: test 3. (d) check dam 1: pretest and test 1. (e) Opening of check dam 2: test 2. (f) Upstream to downstream view of check dam 3 : test 3 .

(Fig. 3a). Despite Ts in the control group, Fig. 2 presents overall agreement near to one for parameter $\mathrm{A}$. That is the ratio question / parameter for parameter $\mathrm{A}$ and test 1 . For parameter $\mathrm{B}$, overall agreement was reached only in the modeoff by one level. That represents lower precision in the B ratings indistinctly of the groups.

However, performance in test 1 contrasts with the one in test 2 . Inspection complexity of bridge 2 was higher due to stream water flowing along the structure's pillars and abutments (Fig. 3b). For parameter A, Table 5 highlights higher frequency of unspecified answers and ordinal scores with standard deviations larger than 1. For Parameter A, Fig. 2 shows accuracy levels below the relative frequency of $70 \%$. Consequently, there is disagreement in the mode score between Vs and Ts, indistinctly of the groups. The presence of erosion in test 2 , i.e., question A1, was mostly rated by participants as "Could not be answered", "No answer" or "No erosion". Moreover, those who reported erosion in the pillar and abutment did not distinguish among erosion presence with or without the stream water along the basis.

For parameter A, in test 3, Fig. 2 shows better performance for the TLG and VLG as compared to the TCG and VCG. The difference in performance could represent some influence of the learning session. However, it also denotes the need for adjusting questions to avoid misunderstandings.
That is the case of question A3, which should explicitly address the status of protection works for downstream scouring in bridges (Fig. 3c). For parameter B, Ts and Vs only reached accuracy levels above $70 \%$ when looking at the mode-off by one level, indistinctly of the test. However, question B3 (presence of islands with shrubs or man-made structures that reduce the opening for the flow) had the lowest precision in Table 5 and Fig. 2. Then, question B3 should be split for better distinguishing presence of islands with vegetation from man-made obstructions.

\subsection{Functional status of check dams for parameters A and $B$}

Table 6 highlights the questions with more serious concerns and standard deviations above 1 . Despite the functional status, the presence of connected elements to the structures contributed to larger standard deviations. Thus, complexity in the inspection was higher due to the presence of a secondary structure in check dam 1 and a retention basin in check dam 2 (Fig. 3d and e).

Figure 4 shows the lower accuracy levels and overall agreement ratio for parameter $\mathrm{A}$ in test 3 . Then, question $\mathrm{A} 1$ was the least accurate for Vs in test 2 and 3. Those results may be explained on the rating scale we used, (see Supplement for check dams). For question A1, rating classes did not distinguish slight deviations from the strong ones. Then, medium concerns were not explicitly within the available options.

In addition, Fig. 4 shows higher frequencies of unspecified answers for questions $\mathrm{A} 2$ and $\mathrm{A} 3$ in test 1 and 2. In test 1 , unspecified answers were due to the water level at the basis of the structure. "Could not be answered" was even the preferred option for the TLG. In test 2 , visibility at the basis of the structure was limited due to the sediment accumulation. Finally, question A4 denoted higher frequencies of unspecified answers for all structures (Table 6 and Fig. 4). Description of question A4 should be reviewed to avoid misunderstanding with question A2. That is the case of connected structures for protection of downstream scouring. Classes to report in question A4 should be extended to consider all possible functional conditions.

For parameter B, questions B1 and B2 have the lowest completeness in pretest and test 1 . Those questions were not relevant for the consolidation check dam. Despite the "Does not apply" option, VLG and TLG still preferred not to answer.

\subsection{Common aspects for the functional status: parameter $\mathrm{C}$ and synthesis}

In questions $\mathrm{C} 1$ and $\mathrm{C} 2$ for bridges and check dams, participants only distinguished the upstream and downstream location from the field inspection (test 1). That is comparing to the pretest results, which was the preliminary inspection test 


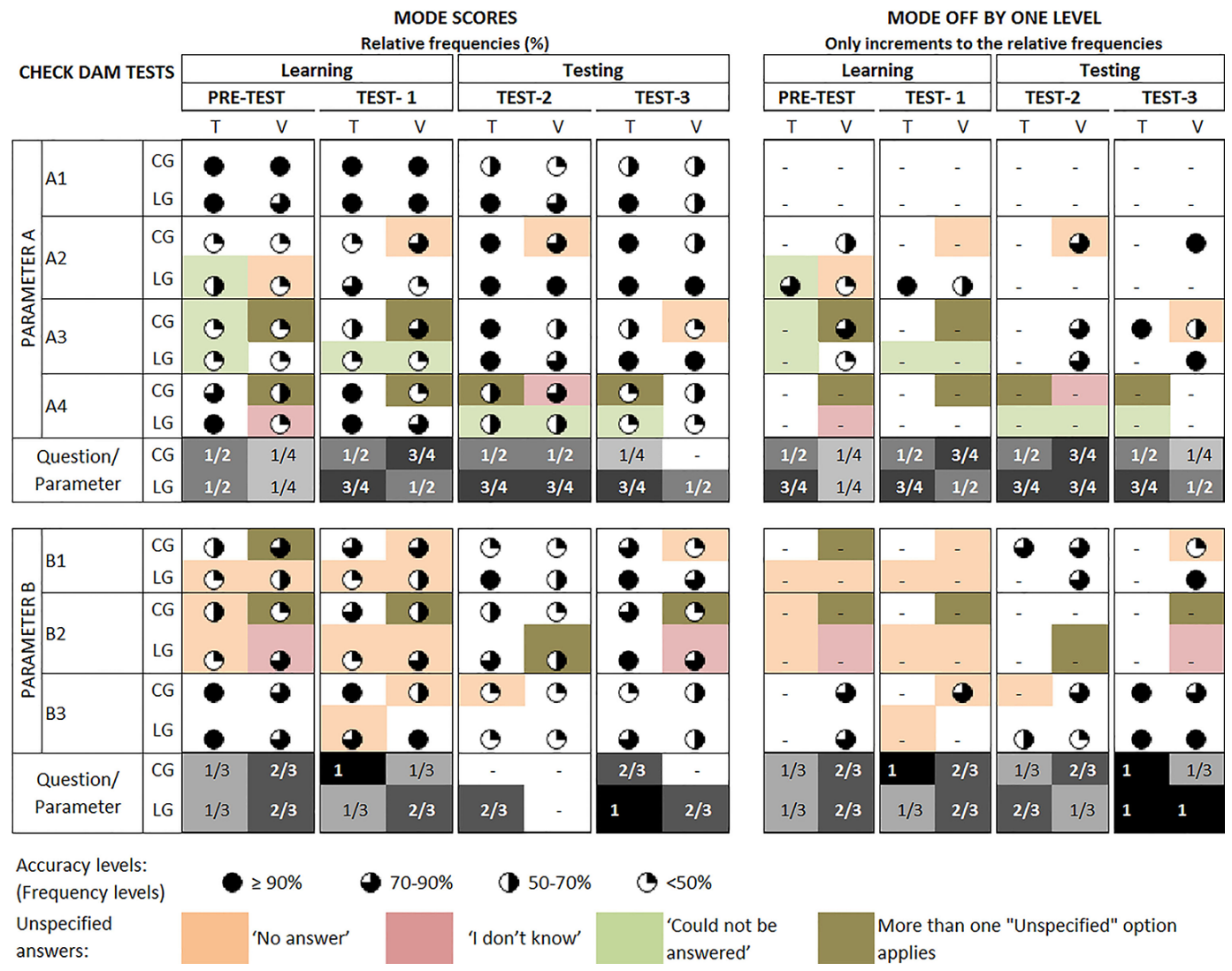

Figure 4. Relative frequencies for Vs and Ts of learning groups (LGs) and control groups (CGs). Parameter A and B in inspection tests for check dams.

to the learning session. For the pretests, mode scores were only assessable during the field inspections (test 1) due to the participants' difficulty in compiling the form in front of a poster (pretest). Similar performance of the pretests holds for check dam 1 and bridge 1, indistinctly of the parameter inspected (Figs. 2-6).

When looking at the overall agreement, the most subjective aspects were the level of erosion at the stream bank (parameter $\mathrm{C}$ ) and synthesis of the inspection. For the first one, the description coming along with the rating classes should be improved. The scheme that supports this aspect should also be adjusted in order to minimize misunderstandings between the left and right bank. For the latter, the synthesis should remain optional for volunteer inspectors. However, Ts did not agree for all structures. Then participants still require a short handout which can be taken with them to the field to support their choices.

\section{Discussion}

First-level inspection of hydraulic structures is a citizen science project that aims to support decisions about obstructions of hydraulic structures, or to pre-screen problems for more technical and detailed inspections. Potential use especially holds on dynamic environments with a large number of hydraulic structures or where financial and human resources are limited (Danielsen et al., 2005; Holub and Hübl, 2008; de Jong, 2013).

In this research, we combined rating scales with ordinal scores to get an indication on the functional status. However, we still acknowledge the usefulness of photo and videos to support detailed descriptions (Dirksen et al., 2013; Yetman, 2002). Regardless of their importance, not all volunteers took photographs. They expressed difficulties to relate the photo record in the form. Then, we made distinction among volunteer data with those obtained by professional staff. Referring to participants' characteristics, both the Ts and Vs were mostly adult men. However, Vs were younger participants, as groups included students. Ts generally had higher level of education than Vs. This can be explained again by the presence of students but also by the fact that volunteering for civil protection does not require high level of education. Most Ts and half of the Vs were local inhabitants of the Fella Basin. Vs who do not live there were mostly the students who live largely in the FVG region.

Compared with data collected by Ts, Vs often had higher variance. Differences in accuracy can be explained from their 


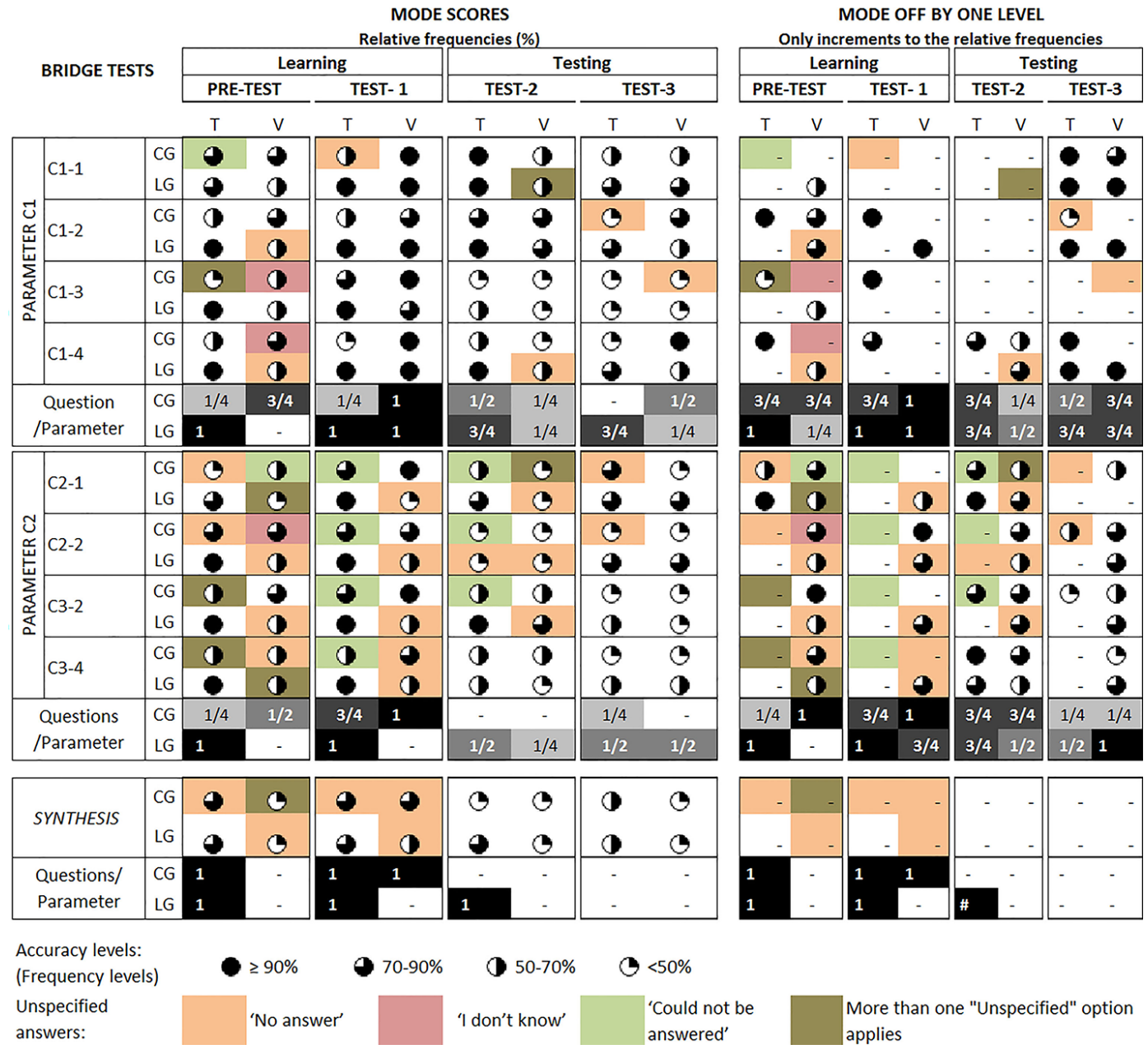

Figure 5. Relative frequencies for Vs and Ts of learning groups (LGs) and control groups (CGs). Parameter C and Synthesis of the inspection tests for bridges.

hazard experience and preliminary knowledge for the inspection of hydraulic structures. The experience with natural hazards varied greatly for all the groups, some participants had never experienced natural hazards when some had more than 10 times. Not surprisingly, Ts had very good a prior knowledge for debris-flow phenomena, functionality of check dams and culverts, as well as on emergency security guidelines. Vs scored lower especially in the VLG.

Survey procedures were discussed with the LG. Thus, forms may be differently interpreted when comparing between the TLG and TCG. Similarly, the preliminary knowledge of geosciences students may also influence their performance in the VCG. That is by comparing with the VLG, which were mostly composed of citizen volunteers of civil protection. Differences between Vs and Ts can evidenced lack of training and unfamiliarity with survey protocols.

We found that the use of rating scales with a range in precision of one level could cope with some variance. Previous studies indicated the advantages of rating classes (Yetman,
2002) and the combination of classes depending on the questions to be answered (Rinderer et al., 2012). However, visual inspections are subjected to various sources of biases, both for the volunteers and technicians. For example, limitations on the accuracy for the recognition of defects, precision to describe defects according to a rating scale and completeness of the inspection reports (Gouveia et al., 2004; Dirksen et al., 2013). Therefore, it was useful to include unspecified options distinguishing limitations such as water level and inspection conditions, which are also complementary information to analyze the reports.

Furthermore, we referred to potential improvements in survey procedures. Rating scales should consider all possible functional conditions, only when distinction among different concerns is possible. Improvements in the forms are still required. For example, a separated form could be defined for culverts to address specific aspects of such structures (Najafi and Bhattachar, 2011). However, surveys procedures should remain as simple as possible. 


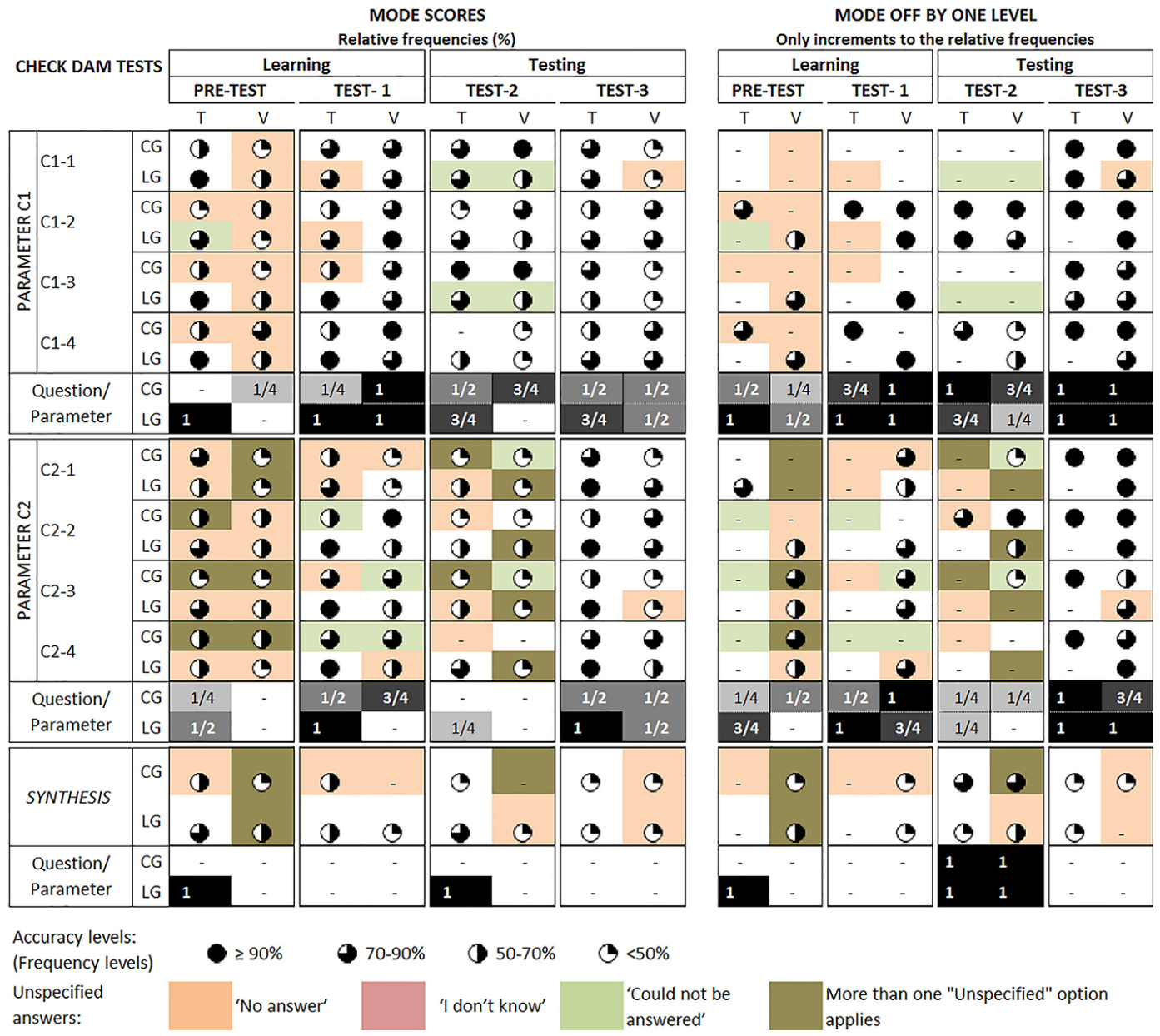

Figure 6. Relative frequencies for Vs and Ts of learning groups (LGs) and control groups (CGs). Parameter C and Synthesis of the inspection tests for check dams.

Despite the needs for improvement, several comments proved the utility of the activity: "as a good initiative to instruct volunteers on the observation of the territory with preventive scope, it joined theory and practice together on the field, it helped to understand and inspect the functionality of the structure".

Nevertheless, iterative design and additional testing is required before making a perennial activity from this pilot. First, improvements on the inspection procedures should be separately tested with technicians to improve robustness of methods. Thus, we could validate the iterative design within the reference group. Then, we could discuss procedures with the technicians for later examination of data and the use for decision-making.

The involvement of a mixed group of participants was interesting for knowledge exchange, particularly in the outdoor session. However, it also facilitated interaction during the inspection tests, which was ideally not desired. Then, replication exercises should be carried out on a separate day for each participant's group to improve consistency on the meth- ods. Finally, participants should have feedback on the quality evaluation following every inspection campaign. It may contribute to maintaining data quality during the design phase but also on a long-term basis.

Moreover, citizen-based approaches require the effective combination of two practical aspects in order to be fully useful: recruiting and training strategies. Then, qualityassurance methods for data collection, comparison and examination (Crall et al., 2011; Riesch and Potter, 2014).

From the social perspective, a cornerstone beyond our research scope is the increasing volunteers' awareness of the water-sediment processes being addressed (Couvet et al., 2008). From the technical perspective, geoinformatic tools and mobile devices could facilitate data collection, access and validation (Newman et al., 2012). Data management systems could support technicians to compare and use collected data for later examination.

In addition, participants could exploit smartphone applications for form compiling, completeness checking, data transferring and photo record. Additional tools could be included, 
Table 5. Evaluation of scores for the data collected in the inspection tests for bridges. The values in bold distinguish the lowest performance.

\begin{tabular}{|c|c|c|c|c|c|c|c|c|c|}
\hline \multirow{2}{*}{$\begin{array}{l}\text { Participant's number } \\
\text { Component questions per parameter } \\
\text { (Rating classes: assigned scores) }\end{array}$} & \multicolumn{3}{|c|}{$\begin{array}{c}36 \\
\text { Test 1. Bridge } 1\end{array}$} & \multicolumn{3}{|c|}{$\begin{array}{c}31 \\
\text { Test 2. Bridge } 2\end{array}$} & \multicolumn{3}{|c|}{$\begin{array}{c}31 \\
\text { Test } 3 . \text { Bridge } 3\end{array}$} \\
\hline & $\bar{X}$ & SD & $\% \mathrm{Us}$ & $\bar{X}$ & SD & $\% \mathrm{Us}$ & $\bar{X}$ & SD & $\% \mathrm{Us}$ \\
\hline \multicolumn{10}{|l|}{ (A) Condition of the structure } \\
\hline $\begin{array}{l}\text { A1. Erosion at the pillar or abutment. } \\
\text { ( } 3 \text { classes: } 1,4 \text { and } 5 \text { ) }\end{array}$ & 1.3 & \pm 1.0 & $3 \%$ & 2.5 & \pm 1.6 & $19 \%$ & 1.0 & - & $3 \%$ \\
\hline $\begin{array}{l}\text { A2. Natural jumps created by the stream. } \\
\text { ( } 2 \text { classes: } 1 \text { and } 5)\end{array}$ & 1.2 & \pm 0.9 & - & 1.7 & \pm 1.5 & $13 \%$ & 1.1 & \pm 0.7 & $3 \%$ \\
\hline $\begin{array}{l}\text { A3. Other damage at the foot of the structure. } \\
\text { ( } 2 \text { classes: } 1 \text { and } 5)\end{array}$ & 1.0 & - & $3 \%$ & 1.9 & \pm 1.7 & $13 \%$ & 1.0 & - & $10 \%$ \\
\hline \multicolumn{10}{|l|}{ (B) Level of obstruction at the structure } \\
\hline $\begin{array}{l}\text { B1. Obstruction upstream } \\
\text { ( } 5 \text { classes: } 1,2,3,4 \text { and } 5)\end{array}$ & 1.3 & \pm 0.5 & - & 1.7 & \pm 0.9 & $3 \%$ & 1.8 & \pm 0.9 & - \\
\hline $\begin{array}{l}\text { B2. Obstruction downstream } \\
(5 \text { classes: } 1,2,3,4 \text { and } 5)\end{array}$ & 1.3 & \pm 0.5 & - & 1.7 & \pm 0.8 & $3 \%$ & 1.5 & \pm 0.6 & $3 \%$ \\
\hline $\begin{array}{l}\text { B3. Islands with vegetation (shrub) or other } \\
\text { man-made obstructions ( } 2 \text { classes: } 1 \text { and } 5 \text { ) }\end{array}$ & 1.7 & \pm 1.5 & - & 2.9 & \pm 2.0 & - & 1.8 & \pm 1.6 & - \\
\hline \multicolumn{10}{|c|}{ (C1) Presence of protection works within $20 \mathrm{~m}$ upstream and downstream } \\
\hline $\begin{array}{l}\text { C1.1. Left bank - upstream } \\
\text { ( } 3 \text { classes: } 1,4 \text { and } 5)\end{array}$ & 4.9 & \pm 0.7 & $3 \%$ & 1.6 & \pm 1.3 & $13 \%$ & 4.4 & \pm 1.2 & - \\
\hline $\begin{array}{l}\text { C1.2. Left bank - downstream } \\
\text { ( } 3 \text { classes: } 1,4 \text { and } 5)\end{array}$ & 4.8 & \pm 0.7 & - & 1.6 & \pm 1.4 & $3 \%$ & 4.4 & \pm 1.0 & $3 \%$ \\
\hline $\begin{array}{l}\text { C1.3. Right bank - upstream } \\
\text { ( } 3 \text { classes: } 1,4 \text { and } 5)\end{array}$ & 5.0 & \pm 0.2 & $6 \%$ & 3.5 & \pm 1.9 & $3 \%$ & 3.1 & \pm 1.8 & $3 \%$ \\
\hline $\begin{array}{l}\text { C1.4. Right bank - downstream } \\
(3 \text { classes: } 1,4 \text { and } 5)\end{array}$ & 4.8 & \pm 0.7 & - & 4.2 & \pm 1.4 & $10 \%$ & 4.5 & \pm 0.8 & - \\
\hline \multicolumn{10}{|c|}{ (C2) Level of erosion at the stream bank within the same distance } \\
\hline $\begin{array}{l}\text { C2.1. Left bank - upstream } \\
(5 \text { classes: } 1,2,3,4 \text { and } 5)\end{array}$ & 1.1 & \pm 0.3 & $19 \%$ & 1.6 & \pm 0.6 & $19 \%$ & 1.6 & \pm 0.9 & $3 \%$ \\
\hline $\begin{array}{l}\text { C2.2. Left bank - downstream } \\
(5 \text { classes: } 1,2,3,4 \text { and } 5)\end{array}$ & 1.1 & \pm 0.3 & $14 \%$ & 2.4 & \pm 1.3 & $16 \%$ & 1.7 & \pm 1.0 & $3 \%$ \\
\hline $\begin{array}{l}\text { C2.3. Right bank - upstream } \\
(5 \text { classes: } 1,2,3,4 \text { and } 5)\end{array}$ & 1.1 & \pm 0.2 & $17 \%$ & 1.3 & \pm 0.5 & $10 \%$ & 2.0 & \pm 0.9 & $3 \%$ \\
\hline $\begin{array}{l}\text { C2.4. Right bank - downstream } \\
(5 \text { classes: } 1,2,3,4 \text { and } 5)\end{array}$ & 1.1 & \pm 0.3 & $22 \%$ & 2.0 & \pm 0.8 & $6 \%$ & 2.3 & \pm 1.3 & - \\
\hline \multicolumn{10}{|l|}{ Synthesis of the inspection } \\
\hline (4 classes: $1,2,4$ and 5 ) & 1.5 & \pm 1.1 & $19 \%$ & 2.6 & \pm 1.5 & $6 \%$ & 3.2 & \pm 1.8 & $6 \%$ \\
\hline
\end{tabular}

$\bar{X}$ : average ordinal score; SD: standard deviation; \%Us: relative frequency of unspecified answers.

such as an embedded glossary or a systematic tag. GPS signal coverage of mobile devices is especially limited in mountain catchments. Therefore, a known ID of the structure may still be relevant. Future research using such applications should address data-quality requirements. Usability should explore advantages for the diversity of volunteers getting involved (Newman et al., 2010).

\section{Conclusions}

Results showed that citizen volunteers could carry out firstlevel inspections with comparable performance to technicians. Differences among the 11 technicians and 25 volunteers do not have a high statistical significance when distinction is done among control and learning groups. However, key points can still be extracted from this data set. Those considerations are relevant for the use of volunteers' data on the 
Table 6. Evaluation of scores for the data collected in the inspection tests for check dams. The values in bold distinguish the lowest performance.

\begin{tabular}{|c|c|c|c|c|c|c|c|c|c|}
\hline \multirow{2}{*}{$\begin{array}{l}\text { Participant's number } \\
\text { Component questions per parameter } \\
\text { (Rating classes: assigned scores) }\end{array}$} & \multicolumn{3}{|c|}{$\begin{array}{c}35 \\
\text { Test 1. Check dam } 1\end{array}$} & \multicolumn{3}{|c|}{$\begin{array}{c}31 \\
\text { Test 2. Check dam } 2\end{array}$} & \multicolumn{3}{|c|}{$\begin{array}{c}31 \\
\text { Test 3. Check dam } 3\end{array}$} \\
\hline & $\bar{X}$ & SD & $\%$ Us & $\bar{X}$ & SD & $\%$ Us & $\bar{X}$ & SD & $\%$ Us \\
\hline \multicolumn{10}{|l|}{ (A) Condition of the structure } \\
\hline $\begin{array}{l}\text { A1. Stream flow passing where it should be } \\
\text { ( } 3 \text { classes: } 1,4 \text { and } 5 \text { ) }\end{array}$ & 1.1 & \pm 0.7 & - & 2.0 & \pm 1.5 & - & 2.0 & \pm 1.4 & - \\
\hline $\begin{array}{l}\text { A2. Status of the check dam } \\
(5 \text { classes: } 1,2,3,4 \text { and } 5)\end{array}$ & 2.2 & \pm 1.5 & $9 \%$ & 1.0 & \pm 0.2 & $6 \%$ & 1.1 & \pm 0.3 & - \\
\hline $\begin{array}{l}\text { A3. Visibility of the basis of the structure. } \\
\text { ( } 5 \text { classes: } 1,2,3,4 \text { and } 5 \text { ) }\end{array}$ & 2.2 & \pm 1.7 & $23 \%$ & 1.3 & \pm 0.6 & $3 \%$ & 1.3 & \pm 0.6 & $3 \%$ \\
\hline $\begin{array}{l}\text { A4. Protection for dowmstream scouring. } \\
\text { ( } 3 \text { classes: } 3,1 \text { and } 5 \text { ) }\end{array}$ & 4.7 & \pm 0.9 & $11 \%$ & 3.2 & \pm 0.6 & $32 \%$ & 1.9 & \pm 1.0 & $16 \%$ \\
\hline \multicolumn{10}{|l|}{ (B) Level of obstruction at the structure } \\
\hline $\begin{array}{l}\text { B1. At the opening of the check dam, if any } \\
\text { ( } 5 \text { classes: } 1,2,3,4 \text { and } 5)\end{array}$ & 1.0 & - & $26 \%$ & 4.4 & \pm 0.8 & - & 2.1 & \pm 0.5 & $3 \%$ \\
\hline $\begin{array}{l}\text { B2. Upstream in the retention basin, if any } \\
\text { ( } 3 \text { classes: } 1,3 \text { and } 5 \text { ) }\end{array}$ & 1.2 & \pm 0.8 & $26 \%$ & 4.0 & \pm 1.4 & $13 \%$ & 1.2 & \pm 0.5 & $16 \%$ \\
\hline $\begin{array}{l}\text { B3. Downstream obstruction } \\
(5 \text { classes: } 1,2,3,4 \text { and } 5)\end{array}$ & 1.1 & \pm 0.2 & $9 \%$ & 2.5 & \pm 1.3 & $3 \%$ & 1.8 & \pm 0.9 & - \\
\hline \multicolumn{10}{|c|}{ (C1) Presence of protection works within $20 \mathrm{~m}$ upstream and downstream } \\
\hline $\begin{array}{l}\text { C1.1. Left bank - upstream } \\
\text { (3 classes: } 1,4 \text { and 5) }\end{array}$ & 1.7 & \pm 1.5 & $6 \%$ & 1.3 & \pm 0.9 & $13 \%$ & 4.4 & \pm 0.8 & $6 \%$ \\
\hline $\begin{array}{l}\text { C1.2. Left bank - downstream } \\
(3 \text { classes: } 1,4 \text { and } 5)\end{array}$ & 4.9 & \pm 0.3 & $3 \%$ & 4.5 & \pm 0.8 & $3 \%$ & 4.6 & \pm 1.0 & - \\
\hline $\begin{array}{l}\text { C1.3. Right bank - upstream } \\
\text { ( } 3 \text { classes: } 1,4 \text { and 5) }\end{array}$ & 4.6 & \pm 1.2 & $6 \%$ & 1.1 & \pm 0.6 & $16 \%$ & 4.0 & \pm 1.3 & - \\
\hline $\begin{array}{l}\text { C1.4. Right bank - downstream } \\
(3 \text { classes: } 1,4 \text { and } 5)\end{array}$ & 4.9 & \pm 0.3 & $3 \%$ & 2.9 & \pm 1.7 & $3 \%$ & 4.6 & \pm 1.0 & $3 \%$ \\
\hline \multicolumn{10}{|c|}{ (C2) Level of erosion at the stream bank within the same distance } \\
\hline $\begin{array}{l}\text { C2.1. Left bank - upstream } \\
(5 \text { classes: } 1,2,3,4 \text { and } 5)\end{array}$ & 1.4 & \pm 0.7 & $26 \%$ & 1.8 & \pm 1.2 & $39 \%$ & 1.3 & \pm 0.4 & $3 \%$ \\
\hline $\begin{array}{l}\text { C2.2. Left bank - downstream } \\
(5 \text { classes: } 1,2,3,4 \text { and } 5)\end{array}$ & 1.2 & \pm 0.5 & $11 \%$ & 1.5 & \pm 0.9 & $19 \%$ & 1.3 & \pm 0.4 & - \\
\hline $\begin{array}{l}\text { C2.3. Right bank - upstream } \\
(5 \text { classes: } 1,2,3,4 \text { and } 5)\end{array}$ & 1.1 & \pm 0.3 & $14 \%$ & 1.9 & \pm 1.2 & $39 \%$ & 1.6 & \pm 0.8 & $6 \%$ \\
\hline $\begin{array}{l}\text { C2.4. Right bank }- \text { downstream } \\
(5 \text { classes: } 1,2,3,4 \text { and } 5)\end{array}$ & 1.1 & \pm 0.3 & $17 \%$ & 2.6 & \pm 1.4 & $23 \%$ & 1.3 & \pm 0.5 & - \\
\hline \multicolumn{10}{|l|}{ Synthesis of the inspection } \\
\hline ( 4 classes: $1,2,4$ and 5) & 3.1 & \pm 1.9 & $11 \%$ & 4.3 & \pm 0.4 & $19 \%$ & 2.7 & \pm 1.4 & $10 \%$ \\
\hline
\end{tabular}

$\bar{X}$ : average ordinal score; SD: standard deviation; \%Us: relative frequency of unspecified answers.

functional status of hydraulic structures. It may also provide some guidance to researchers and practitioners interested in citizen-based data.

1. Volunteers could carry out first-level inspections with comparable performance to technicians, but with a prerequired range in precision. However, survey proce- dures that are clear enough require iterative design and testing to avoid uncertainty and misunderstandings.

2. In spite of the need to standardize reports, unstructured data such as comments and pictures are still required by managers to validate completeness and precision of volunteers' data. Then, the systematic tagging and referencing of that data is crucial. 
Table 7. Feedback of participants to initiate corrective actions in survey procedures.

\begin{tabular}{|c|c|c|}
\hline Feedback form & Comments received & Corrective actions \\
\hline $\begin{array}{l}\text { Was the inspection form clear } \\
\text { enough to carry out the inspection? }\end{array}$ & $\begin{array}{l}\text { Protection works for scouring should } \\
\text { be inspected not only for check dams } \\
\text { but also for bridges when it applies. } \\
\text { For bridges, obstructions in the floodplain } \\
\text { should be also reported. } \\
\text { Upstream obstruction should be reported for open } \\
\text { and consolidation check dams. }\end{array}$ & $\begin{array}{l}\text { Rating classes and schemes will be adapted } \\
\text { according to participants' comments and } \\
\text { recommendations from the results section. } \\
\text { Brief guidelines and glossary must be provided } \\
\text { together with the inspection form. }\end{array}$ \\
\hline $\begin{array}{l}\text { Did you find the options } \\
\text { provided in the form useful } \\
\text { to answer the questions? }\end{array}$ & $\begin{array}{l}\text { When possible, rating scales with three or two classes } \\
\text { should be extended to rate all possible status. } \\
\text { Presence of human infrastructure should be } \\
\text { open question to report other infrastructure } \\
\text { besides roads and buildings. }\end{array}$ & $\begin{array}{l}\text { To avoid misunderstandings, the question regarding } \\
\text { the presence of protection works will better refer to } \\
\text { their length within the control distance. } \\
\text { The form will emphasize to report the infrastructure } \\
\text { that may be affected in case of high water levels. }\end{array}$ \\
\hline $\begin{array}{l}\text { Which aspects you did not } \\
\text { like about the activity? }\end{array}$ & $\begin{array}{l}\text { All structures to inspect should have available } \\
\text { information for the function type. } \\
\text { Participants with technical background } \\
\text { considered the indoor session long while } \\
\text { citizen-volunteers requested more time } \\
\text { to better understand the theory and } \\
\text { to carry out the inspections. } \\
\text { The inspection in front of the poster } \\
\text { could be better used after both theory } \\
\text { and practice have been explained. }\end{array}$ & $\begin{array}{l}\text { Information regarding the type of structure } \\
\text { will be always precompiled in the form. } \\
\text { The learning should start directly with } \\
\text { the outdoor session and finishes with } \\
\text { the indoor session. } \\
\text { The indoor session will be carried out } \\
\text { separately for each group of participants. } \\
\text { Interaction between groups will be limited } \\
\text { to the outdoor session. }\end{array}$ \\
\hline
\end{tabular}

3. Unspecified answers may persist according to the complexity of connected elements to the structure, and the unexpected conditions for the inspection. Rating classes should specify when water or sediment did not allow the assessment. However, other options should be limited to facilitate the later examination of data.

4. Volunteer ratings should be considered as first-level assessment. Managers could combine these ratings to get indexes on the status of the structure at parameter level. However, an indication of the overall completeness per parameter would still be needed for the later examination.

5. The use of scores to convert volunteer ratings is important for getting an indication of the functional status. Since the rating scales are expressed in linguistic terms, ratings could be converted into numbers by using a fuzzy set theory instead of ordinal scores. Conversion of the volunteers' data using scales of fuzzy terms could handle the pre-required ranges in precision (e.g., from low to very low).

Important considerations to improve and promote citizen science projects are firstly related to limitations on citizen involvement due to different culture of volunteer activities and interest in participating. Secondly, training is relevant for the performance of volunteers, but also for increasing awareness and preparedness on the causes and consequences of hydro meteorological hazards (Enders, 2001). For the first one, students are an alternative approach for the citizens' recruitment, where there is limited volunteer culture. Universities could involve students of geosciences or social sciences to gain practical knowledge or better understand their territory (Savan et al., 2003).

For the latter, future research should test the effectiveness of the learning session according to differences in preliminary knowledge of participants. In the study area, volunteer groups offered opportunities to carry out first-level inspections. However, replication exercises are still needed in other study areas to improve the consistency and robustness of the data evaluation. In addition, survey procedures could be adapted to other target groups, e.g., last-year high school students who are not aware/involved in management activities. That could be an alternative approach to enhance their awareness of hydro-meteorological hazards. 


\section{Appendix A}

Table A1. Participants' characteristics for Vs and Ts of learning groups (LGs) and control groups (CGs).

\begin{tabular}{|c|c|c|c|c|}
\hline $\begin{array}{l}\text { Participant's } \\
\text { number }\end{array}$ & $\begin{array}{c}\text { TLG } \\
4^{*}\end{array}$ & $\begin{array}{c}\text { TCG } \\
5\end{array}$ & $\begin{array}{c}\text { VLG } \\
18\end{array}$ & $\begin{array}{c}\text { VCG } \\
7\end{array}$ \\
\hline \multicolumn{5}{|l|}{ Age (years) } \\
\hline $16-24$ & - & - & 7 & 4 \\
\hline $25-44$ & 2 & 2 & 7 & 2 \\
\hline $45-64$ & 2 & 3 & 4 & 1 \\
\hline \multicolumn{5}{|l|}{ Gender } \\
\hline Female & - & 1 & 3 & 2 \\
\hline Male & 4 & 4 & 15 & 5 \\
\hline \multicolumn{5}{|c|}{ Highest level of education } \\
\hline Elementary school & - & - & 2 & - \\
\hline College & - & - & 4 & 2 \\
\hline High school & 1 & 1 & 10 & 3 \\
\hline Technical degree & - & - & 2 & 2 \\
\hline Master's degree & 2 & 3 & - & - \\
\hline $\mathrm{PhD}$ & 1 & 1 & - & - \\
\hline \multicolumn{5}{|c|}{ Period of residence in the Fella Basin } \\
\hline More than 20 years & 3 & 4 & 7 & 5 \\
\hline Never & 1 & 1 & 11 & 2 \\
\hline \multicolumn{5}{|c|}{ Period of residence in the FVG region } \\
\hline Less than a year & - & - & 2 & - \\
\hline $1-5$ years & - & - & 1 & 1 \\
\hline More than 20 years & 4 & 5 & 14 & 4 \\
\hline Never & - & - & 1 & 2 \\
\hline
\end{tabular}

Table A1. Continued.

\begin{tabular}{lcccc}
\hline Participant's & TLG & TCG & VLG & VCG \\
number & $4^{*}$ & 5 & 18 & 7 \\
\hline \multicolumn{2}{l}{ Experiences with floods } & & & \\
\hline Never & 1 & 1 & 6 & 3 \\
Once & - & - & 1 & 1 \\
2-5 times & 2 & 2 & 8 & 3 \\
6-10 times & - & - & 1 & - \\
More than 10 times & 1 & 2 & 1 & - \\
No data & - & - & 1 & - \\
\hline Experiences with debris flows & & & \\
\hline Never & 1 & 1 & 8 & 4 \\
Once & - & - & - & - \\
2-5 times & 2 & 2 & 4 & 3 \\
6-10 times & 1 & 1 & 4 & - \\
More than 10 times & - & 1 & 1 & - \\
No data & - & - & 1 & - \\
\hline Experiences with landslides & & & \\
\hline Never & - & 2 & 7 & 3 \\
Once & - & - & 2 & 2 \\
2-5 times & 2 & 1 & 3 & 2 \\
6-10 times & - & 1 & 3 & - \\
More than 10 times & 2 & 1 & 2 & - \\
No Data & - & - & 1 & - \\
\hline A prior knowledge $\%$ of correct answers on 20 questions) \\
\hline 0-25\% & - & - & 1 & - \\
26-50\% & - & - & 3 & - \\
51-75\% & - & - & 8 & 6 \\
76-100\% & 4 & 5 & 6 & 1 \\
\hline * & & \\
\hline
\end{tabular}

* 2 TLG did not fill the questionnaire. Table summarize data for 34 participants. 


\section{The Supplement related to this article is available online at doi:10.5194/nhess-14-2681-2014-supplement.}

Acknowledgements. This research was conducted in collaboration with civil protection, technical services and the local authorities of FVG. Students of the Università degli Studi di Trieste were also participants of the research. Authors would like to thank Roxana Ciurean and Chiara Calligaris for their valuable support during the fieldwork period in terms of organizational aspects. We would also like to thank reviewers for their comments that help to improve the manuscript. This work is part of the Marie Curie ITN changing hydro-meteorological risks as analyzed by a new generation of European scientists (CHANGES project), which is funded by the European community's seventh framework programme FP7/2007-2013 under grant agreement no. 263953.

Edited by: F. Guzzetti

Reviewed by: two anonymous referees

\section{References}

ADBVE (Autorità di bacino dei fiumi dell'Alto Adriatico): Progetto di Piano Stralcio per l'Assetto Idrogeologico del bacino idrogeografico del fiume Fella, PAI-FELLA, available at: http:// pai.adbve.it/PAI_Fella/index_fella.html, last access: 7 July 2014, 2012 (in Italian).

Bjorkland, R., Pringle, C., and Newton, B.: A Stream Visual Assessment Protocol (SVAP) for Riparian landowners, Environ. Monit. Assess., 68, 99-125, doi:10.1023/A:1010743124570, 2001.

Bonney, R., Cooper, C. B., Dickinson, J. L., Kelling, S., Phillips, T., Rosenberg, K. V., and Shirk, J.: Citizen science: a developing tool for expanding science knowledge and scientific literacy, BioScience, 59, 977-984, doi:10.1525/bio.2009.59.11.9, 2009.

Bordogna, G., Carrara, P., Criscuolo, L., Pepe, M., and Rampini, A.: A linguistic decision making approach to assess the quality of volunteer geographic information for citizen science, Information Sciences, 258, 312-327, doi:10.1016/j.ins.2013.07.013, 2014.

Borga, M., Boscolo, P., Zanon, F., and Sangati, M.: Hydrometeorological Analysis of the 29 August 2003 Flash Flood in the Eastern Italian Alps, J. Hydrometeorol., 8, 1049-1067, doi:10.1175/JHM593.1, 2007.

Brandon, A., Spyreas, G., Molano-Flores, B., Caroll, C., and Ellis, J.: Can volunteers provide reliable data for forest vegetation surveys?, National Areas Journal, 23, 254-262, 2003.

Burke Engineering, C. B.: Indiana Drainage Handbook, an Administrative and Technical Guide for Activities within Indiana Streams, CBBEL, Indianapolis, Indiana, available at: http: //www.in.gov/dnr/water/files/allhbook.pdf, last access: 4 July 2013, 1999.

Calligaris, C. and Zini, L.: Debris Flow Phenomena: A Short Overview?, in: Earth Sciences, edited by: Imran Ahmad Dar, InTech, ISBN: 978-953-307-861-8, doi:10.5772/29786, 2012.
Cifelli, R., Doesken, N., Kennedy, P., Carey, L. D., Rutledge, S. A., Gimmestad, C., and Depue, T.: The Community Collaborative Rain, Hail, and Snow Network: informal education for scientists and citizens, B. Am. Meteorol. Soc., 86, 1069-1077, doi:10.1175/BAMS-86-8-1069, 2005.

Conrad, C. and Hilchey, K.: A review of citizen science and community-based environmental monitoring: issues and opportunities, Environ. Monit. Assess., 176, 273-291, doi:10.1007/s10661-010-1582-5, 2011.

Couvet, D., Jiguet, F., Julliard, R., Levrel, H., and Teyssedre, A.: Enhancing citizen contributions to biodiversity science and public policy, Interdiscipl. Sci. Rev., 33, 95-103, doi:10.1179/030801808X260031, 2008.

Crall, A. W., Newman, G. J., Jarnevich, C. S., Stohlgren, T. J., Waller, D. M., and Graham, J.: Improving and integrating data on invasive species collected by citizen scientists, Biol. Invasions, 12, 3419-3428, doi:10.1007/s10530-010-9740-9, 2010.

Danielsen, F., Burgess, N. D., and Balmford, A.: Monitoring matters: examining the potential of locally-based approaches, Biodivers. Conserv., 14, 2507-2542, doi:10.1007/s10531-005-8375$0,2005$.

de Jong, C.: Linking ICT and society in early warning and adaptation to hydrological extremes in mountains, Nat. Hazards Earth Syst. Sci., 13, 2253-2270, doi:10.5194/nhess-13-22532013, 2013.

Devictor, V., Whittaker, R. J., and Beltrame, C.: Beyond scarcity: citizen science programmes as useful tools for conservation biogeography, Divers. Distrib., 16, 354-362, doi:10.1111/j.14724642.2009.00615.x, 2010.

Dirksen, J., Clemens, F. H. L. R., Korving, H., Cherqui, F., Le Gauffre, P., Ertl, T., Plihal, H., Müller, K., and Snaterse, C. T. M.: The consistency of visual sewer inspection data, Struct. Infrastruct. E., 9, 214-228, doi:10.1080/15732479.2010.541265, 2013.

Enders, J.: Measuring community awareness and preparedness for emergencies, Australian Journal of Emergency Management, 16, 52-58, 2001.

Engel, S. R. and Voshell Jr., J. R.: Volunteer biological monitoring: can it accurately assess the ecological condition of streams?, American Entomologist, 48, 164-177, 2002.

EPA: Volunteer Stream Monitoring: A Methods Manual, United States Environmental Protection Agency, Washington, DC, available at: http://water.epa.gov/type/rsl/monitoring/upload/2002_ 08_13_volunteer_stream_stream.pdf, last access: 9 February 2014, 1997.

European Commission: Directive 2007/60/EC of the European Parliament and of the Council of 23 October 2007 on the Assessment and Management of Flood Risks, available at: http://eur-lex.europa.eu/legal-content/EN/TXT/?uri=CELEX: 32007L0060, last access: 9 February 2014, 2007.

European Commission: Civil Protection - Community Cooperation in the Field of Civil Protection, Humanitarian Aid and Civil Protection, available at: http://ec.europa.eu/echo/files/ civil_protection/vademecum/menu/3.html, last access: 9 February 2014, 2012.

Flanagin, A. J. and Metzger, M. J.: The credibility of volunteered geographic information, GeoJournal, 72, 137-148, doi:10.1007/s10708-008-9188-y, 2008. 
Fore, L. S., Paulsen, K., and O'Laughlin, K.: Assessing the performance of volunteers in monitoring streams, Freshwater Biol., 46, 109-123, doi:10.1111/j.1365-2427.2001.00640.x, 2001.

Galloway, A. W. E., Tudor, M. T., and Haegen, W. M. V.: The reliability of citizen science: a case study of Oregon White Oak stand surveys, Wildlife Soc. B., 34, 1425-1429, doi:10.2193/00917648(2006)34[1425:TROCSA]2.0.CO;2, 2006.

Gollan, J., Bruyn, L. L., Reid, N., and Wilkie, L.: Can volunteers collect data that are comparable to professional scientists?, a study of variables used in monitoring the outcomes of ecosystem rehabilitation, Environ. Manage., 50, 969-978, doi:10.1007/s00267-012-9924-4, 2012.

Gommerman, L. and Monroe, M. C.: Lessons Learned from Evaluations of Citizen Science Programs, School of Forest Resources and Conservation, Florida Cooperative Extension Service, Institute of Food and Agricultural Sciences (IFAS), University of Florida, (FOR291), available at: http://edis.ifas.ufl.edu/fr359, last access: 9 February 2014, 2012.

Goodchild, M. F.: Citizens as sensors: the world of volunteered geography, GeoJournal, 69, 211-221, doi:10.1007/s10708-0079111-y, 2007.

Goodchild, M. F. and Li, L.: Assuring the quality of volunteered geographic information, Spatial Statistics, 1, 110-120, doi:10.1016/j.spasta.2012.03.002, 2012.

Gouveia, C. and Fonseca, A.: New approaches to environmental monitoring: the use of ICT to explore volunteered geographic information, GeoJournal, 72, 185-197, doi:10.1007/s10708-0089183-3, 2008

Gouveia, C., Fonseca, A., Câmara, A., and Ferreira, F.: Promoting the use of environmental data collected by concerned citizens through information and communication technologies, J. Environ. Manage., 71, 135-154, doi:10.1016/j.jenvman.2004.01.009, 2004.

Holub, M. and Fuchs, S.: Mitigating mountain hazards in Austria - legislation, risk transfer, and awareness building, Nat. Hazards Earth Syst. Sci., 9, 523-537, doi:10.5194/nhess-9-5232009, 2009.

Holub, M. and Hübl, J.: Local protection against mountain hazards - state of the art and future needs, Nat. Hazards Earth Syst. Sci., 8, 81-99, doi:10.5194/nhess-8-81-2008, 2008.

Hudson-Smith, A., Batty, M., Crooks, A., and Milton, R.: Mapping for the masses: accessing Web 2.0 through crowdsourcing, in: Working Paper Series - University College of London for Advanced Spatial Analysis, Centre for Advanced Spatial Analysis University College London, London, UK, available at: http://eprints.ucl.ac.uk/15198/1/15198.pdf, last access: 9 February 2014, Paper 143, 1-18, 2008.

Jakob, M. and Hungr, O.: Debris Flow Phenomena, Praxis, Berlin, 2005.

Jordan, R. C., Brooks, W. R., Howe, D. V., and Ehrenfeld, J. G.: Evaluating the performance of volunteers in mapping invasive plants in public conservation lands, Environ. Manage., 49, 425434, doi:10.1007/s00267-011-9789-y, 2011.

Mazzorana, B., Hübl, J., Zischg, A., and Largiader, A.: Modelling woody material transport and deposition in alpine rivers, Nat. Hazards, 56, 425-449, doi:10.1007/s11069-009-9492-y, 2010.

Molinari, D., Menoni, S., Aronica, G. T., Ballio, F., Berni, N., Pandolfo, C., Stelluti, M., and Minucci, G.: Ex post damage assess- ment: an Italian experience, Nat. Hazards Earth Syst. Sci., 14, 901-916, doi:10.5194/nhess-14-901-2014, 2014.

Najafi, M. and Bhattachar, D. V.: Development of a culvert inventory and inspection framework for asset management of road structures, Journal of King Saud University - Science, 23, 243 254, doi:10.1016/j.jksus.2010.11.001, 2011.

Newman, G., Zimmerman, D., Crall, A., Laituri, M., Graham, J., and Stapel, L.: User-friendly web mapping: lessons from a citizen science website, Int. J. Geogr. Inf. Sci., 24, 1851-1869, doi:10.1080/13658816.2010.490532, 2010.

Newman, G., Wiggins, A., Crall, A., Graham, E., Newman, S., and Crowston, K.: The future of citizen science: emerging technologies and shifting paradigms, Front. Ecol. Environ., 10, 298-304, doi:10.1890/110294, 2012.

Nicholson, E., Ryan, J., and Hodgkins, D.: Community data-where does the value lie? Assessing confidence limits of community collected water quality data, Water Sci. Technol., 45, 193-200, 2002.

Ohio Department of Transportation: Manual of Bridge Inspection, Ohio Department of Transportation, Federal Highway Administration, Ohio, 2010.

Province of British Columbia: Flood Protection Works Inspection Guide, Water Management Branch, Public Safety Section, British Columbia, Canada, 2000.

Provinzia Autonoma di Bolzano - Alto Adige: Bestandsaufnahme von Wasserbauwerken der Wildbachverbauung, EF 30 - EF30 Sperrenevaluierung Quick Version, 2006 (in German).

Protezione Civile della Regione FVG: Formazione, Campus Virtuale, available at: http://www.protezionecivile.fvg.it/ProtCiv/ default.aspx/81-formazione.htm, last access: 7 July 2014, 2009.

Remaître, A., Malet, J.-P., and Maquaire, O.: Morphology and sedimentology of a complex debris flow in a clay-shale basin, Earth Surf. Proc. Land., 30, 339-348, doi:10.1002/esp.1161, 2005.

Riesch, H. and Potter, C.: Citizen science as seen by scientists: methodological, epistemological and ethical dimensions, Public Underst. Sci., 23, 107-120, doi:10.1177/0963662513497324, 2014.

Rinderer, M., Kollegger, A., Fischer, B. M. C., Stähli, M., and Seibert, J.: Sensing with boots and trousers - qualitative field observations of shallow soil moisture patterns, Hydrol. Process., 26, 4112-4120, doi:10.1002/hyp.9531, 2012.

Savan, B., Morgan, A. J., and Gore, C.: Volunteer environmental monitoring and the role of the universities: the case of citizens' environment watch, Environ. Manage., 31, 561-568, doi:10.1007/s00267-002-2897-y, 2003.

Seeger, C. J.: The role of facilitated volunteered geographic information in the landscape planning and site design process, GeoJournal, 72, 199-213, doi:10.1007/s10708-008-9184-2, 2008.

Servizio Forestale FVG: Catasto Opere Iidraulico Forestali, Manuale Tecnico, Allegato A. Schede di Rilevo, 2002.

Snäll, T., Kindvall, O., Nilsson, J., and Pärt, T.: Evaluating citizenbased presence data for bird monitoring, Biol. Conserv., 144, 804-810, doi:10.1016/j.biocon.2010.11.010, 2011.

Tweddle, J., Robinson, L., Pocock, M., and Roy, H.: Guide to Citizen Science: Developing, Implementing and Evaluating Citizen Science to Study Biodiversity and the Environment in the UK, Natural History Museum, London, 2012. 
United Nations: Hyogo Framework for Action 20052015: Building the Resilience of Nations and Communities to Disasters, Kobe, Japan, 18-22, available at: http://www.unisdr.org/2005/wcdr/intergover/official-doc/ L-docs/Hyogo-framework-for-action-english.pdf, last access: 9 February 2014, 2005.

Uzielli, M., Nadim, F., Lacasse, S., and Kaynia, A. M.: A conceptual framework for quantitative estimation of physical vulnerability to landslides, Eng. Geol., 102, 251-256, doi:10.1016/j.enggeo.2008.03.011, 2008. von Maravic, P.: Evaluation of the Physical Vulnerability of Check Dams Exposed to the Impact of Torrential Processes Through Experimental Analysis, Msc. thesis, University of Padua, Faculty of Agriculture, Departments of Land and Agro-forestry Systems, 2010.

Yetman, K. T.: Using Maryland's stream corrido survey to prioritize watershed restoration efforts, J. Am. Water Resour. As., 38, 905914, doi:10.1111/j.1752-1688.2002.tb05533.x, 2002. 